\title{
THAY ĐỔI VỊ GIÁC SAU PHẪU THUÂTT VIÊM TAI GIŨ̃a MẠN TÍNH
}

\author{
Đào Trung Dũng1, Ngô Thu Trang², Nguyễn Văn Luận ${ }^{3}$
}

\section{TÓM TẮT}

Mục tiêu: Nghiên cứu thay đổi vị giác sau phẫu thuât viêm tai giữa mạn tính. Đối tượng và phương pháp: Nghiên cứu mô tả tiến cứu, gồm 58 bệnh nhân (15 nam và 43 nữ, tuổi từ 18 đến 68 năm), được chẩn đoán viêm tai giữa mạn tính và phẫu thuật chỉnh hình tai giữa, được đánh giá ngưỡng vị giác với bốn vị cơ bản (chua, ngọt, măn, đắng) trước và sau mổ. Kết quả: Tỷ lệ bệnh nhẩn xuất hiện thay đổi vị giác sau mổ là 15,5\% (1ngày), 13,8\% (1tuân), 3,4\% (1tháng), 0\% (3tháng). Bệnh nhân ở ba nhóm thừng nhĩ nguyên vẹn, đụng dập và đứt đều tăng ngưỡng vị giác, trong đó chỉ nhóm đứt thừng nhĩcó tăng ngưỡng vị giác rõ tai thời điểm 1 ngày với vi chua, măn, đắng $(p<0,05), 1$ tuần với vị ngọt, mặn, đắng $(p<0,05)$. Tại thời điểm 1 tháng, ngưỡng vị giác với vị mặn và chua còn tăng $(p>0,05)$. Kết luận: Thay đổi ngưỡng vị giác chủ yếu xảy ra trong vòng 1 tháng sau mồ. Ngưỡng vị giác tăng cùng mức độ tổn thương thừng nhĩ, ảnh hưởng rõ nhất với vị mặn và chua. Sau 3 tháng, không còn bệnh nhân nào có cảm giác thay đổi vị giác trên lâm sàng. tính.

Từ khoá: vị giác, thừng nhĩ, viêm tai giữa mạn

\section{SUMMARY}

GUSTATORY CHANGES AFTER SURGERY FOR CHRONIC SUPPURATIVE OTITIS MEDIA

Objectives: To investigate the gustatory changes after surgery for chronic suppurative otitis media. Patients and Methods: A prospective study was conducted on 58 patients (15 men and 43 women, aged from 18 to 68 years), who were diagnosed with chronic suppurative otitis media and underwent tympanoplasty. All patients were evaluated for taste thresholds with four basic tastes (sour, sweet, salty and bitter) before and after surgery. Results: The rate of patients who had taste changesafter surgery was $15.5 \%$ at one day, $13.8 \%$ at one week, $3.4 \%$ at one month, and $0 \%$ at three months. Taste thresholds of patients in the groups of intact, stretched, and sectioned chorda tympani increased, in which only patients in the sectioned nerve group had their thresholdssignificantly elevated at one day with sour, salty, bitter tastes $(p<0.05)$, at one week with sweet, salty, bitter tastes $(p<0.05)$. At one month, the taste thresholds for salty and sour tastes were still greater than before surgery $(p>0.05)$. Conclusions: Changes in taste thresholds mainly occurred within one month

\footnotetext{
${ }^{1}$ Trường Đai hoc Y hà Nôi

${ }^{2}$ Bệnh viện hữu nghị Việt Nam Cu Ba

${ }^{3}$ Bềnh viện Tai mũi họng TW
}

Chịu trách nhiệm chính: Đào Trung Dũng

Email: daotrungdung@hmu.edu.vn

Ngày nhận bài: 4.01.2021

Ngày phản biên khoa hoc: 5.3.2021

Ngày duyệt bài: 15.3.2021 after surgery. Taste thresholdsproportionally increased with the degree of chorda tympani injury, in which the salty and sour tastes were most affected. After three months, there was no patient toreportchanges in taste sensation.

Keywords: gustatory, chorda tympani, chronic suppurative otitis media.

\section{I. ĐẶT VẤN ĐỀ}

Vị giác đóng vai trò rất quan trọng trong cuộc sống, giúp chúng ta thưởng thức vị ngon khi ăn uống cũng như phát hiện một số chất có tính độc với cơ thể như vị chua của acid, ... Rối loạn chức năng vị giác có thể dẫn đến giảm cảm giác thèm ăn, sụt cân, suy dinh dưỡng. Theo Hoffman, ở Mỹ có khoảng 1,1 triệu người bị các rối loạn vị giác. ${ }^{1}$

Thừng nhĩ là nhánh của thân kinh mặt, chi phối cảm nhận vị giác cho 2/3 trước lưỡi và tiết dịch cho tuyến nước bọt dưới hàm, dưới lưỡi cùng bên. Xuất phát từ đoạn xương chũm của thân kinh mặt, thừng nhĩ chạy qua hòm tai mà không có vỏ xương bao bọc. Vì vậy, thửng nhĩ dễ bị tổn thương do viêm nhiễm hay sang chấn trong quá trình phẫu thuật ở tai giữa. 2,3

Phẫu thuật viêm tai giữa mạn tính nhằm mục tiêu loại bỏ bệnh tích, phục hồi khả năng nghe và ngăn ngừa chảy mủ tai tái phát. Thống kê cho thây khoảng 15-22\% bệnh nhân sau phẫu thuật tai giữa xuất hiện triệu chứng của tổn thương thừng nhĩ với các biểu hiện lâm sàng như khô miệng, giảm và mất vị giác, vị kim loại bất thường. ${ }^{4}$ Tuy nhiên, số lượng nghiên cứu về rối loạn vị giác sau phâuu thuật tai vẫn còn hạn chế, chứng tỏ đây là vấn đề chưa nhận được quan tâm đúng mức. Vì vậy, nghiên cứu này được tiến hành nhằm tìm hiểu sự thay đổi vị giác sau phẫu thuật viêm tai giữa mạn tính.

\section{II. ĐỐI TƯƠNG VÀ PHƯƠNG PHÁP NGHIÊN CỨU}

Nghiên cứu mô tả tiến cứu các bệnh nhân được chẩn đoán viêm tai giữa mạn tính, chưa phẩu thuật tai lần nào, được phẫu thuật chỉnh hình tai giữa, được đánh giá chức năng vị giác trước và sau phẫu thuật trong khoảng thời gian từ tháng 9/2014 đến tháng 9/2015 tại Khoa Tai Mũi Họng, Bệnh viện Bạch Mai và Khoa Tai và Tai thần kinh, Bệnh viện Tai Mũi Họng Trung ương. Tiêu chuẩn loại trừ gồm có tiền sử liệt mặt, chấn thương tai, đang mắc bệnh nội khoa hoặc sử dụng thuốc có thể ảnh hưởng đến vị giác.

Trước mổ một ngày, bệnh nhân được hỏi 
bệnh, khám lâm sàng, đo ngưỡng vị giác. Sau mổ, bệnh nhân được về thay đổi cảm nhận vị giác (giảm, mất, vị bất thường), đo ngương vị giác tại các thời điểm một ngày, một tuần, một tháng. Bộ dung dịch thử vị giác gồm bốn chất thử với các vị ngọt (đường sucrose), mặn (muối $\mathrm{NaCl}$ ), chua (acid citric), đắng (quinine hydrochloride), pha thành dung dịch với nồng độ khác nhau bằng phương pháp pha loãng với nước cất, sử dụng cân Chyo MG-500 (Micro Precision Calibration Inc., Nhật Bản) (Bảng 1). Nước cất được sử dụng để làm dung dịch chứng.

Bảng 1. Bộ dung dịch thử vị giác (nồng độ: $\left.10^{-5} \mathrm{~g} / \mathrm{ml}\right)$

\begin{tabular}{|c|c|c|c|}
\hline Ngọt & Mặn & Chua & Đăng \\
\hline 0,0025 & 0,0004 & 0,0005 & 0,0000125 \\
\hline 0,005 & 0,0008 & 0,001 & 0,000025 \\
\hline 0,01 & 0,0016 & 0,002 & 0,00005 \\
\hline 0,02 & 0,0032 & 0,004 & 0,0001 \\
\hline 0,04 & 0,0064 & 0,008 & 0,0002 \\
\hline 0,08 & 0,0128 & 0,016 & 0,0004 \\
\hline
\end{tabular}

Quy trình thử vị giác: trước khi thử một giờ, bệnh nhân được yêu câu không ăn uống gì khác ngoài uống nước. Bệnh nhân há miệng, thè lưỡi, vi trí thử ở $2 / 3$ trước lưỡi, cách đầu lưỡi $1 \mathrm{~cm}$. Bắt đầu từ nửa lưỡi bên tai bệnh, nhỏ 1 giọt nước cất làm chứng. Sau đó nhỏ một giọt dung dịch thử, bắt đầu từ nồng độ thấp nhất, giữ trong vòng 20 giây. Ở mỗi nồng độ thử 3 lần, cách nhau 30 giây. Trước khi chuyển sang vị khác, bệnh nhân được súc miệng sạch bằng nước cất. Bệnh nhân sẽ được hỏi về cảm nhận với vị đang được thử để đánh giá ngưỡng vị giác, bao gồm ngưỡng phát hiện (là nồng độ thấp nhất của dung dịch thử được nhận định có vị khác với nước cất đúng ít nhất 2 trong 3 lần thử) và ngưỡng phân biệt (là nồng độ thấp nhất xác định đúng vị gì ít nhất 2 trong 3 lần thử).

Cảm nhận vị giác và ngưỡng vị giác được đối chiếu với mức đô tổn thương thừng nhĩ được quan sát trong mổ (nguyên vẹn, đụng dập, đút).

Kết quả được xử lí bằng phần mềm SPSS 16.0 (SPSS Inc., Chicago, Illinois), sử dụng t-test với kiểm định hai phía nhằm so sánh hai trung bình và ANOVA để so sánh nhiều trung bình. Sự khác biệt có ý nghĩa thống kê với $p<0,05$.

\section{KẾT QUẢ NGHIÊN CỨU}

Nghiên cứu gồm 58 bệnh nhân (15 nam và 43 nữ), tuổi trung bình $39,0 \pm 13,1$ tuổi (từ 18 đến 68 tuổi). Tất cả các bệnh nhân đều bị viêm tai giữa mạn tính không có cholesteatoma một bên, tai giửa bên đối diện không có bệnh lí (tai lành). Trong mổ, tình trạng thừng nhĩ được ghi nhận gồm 46/58 (79,3\%) nguyên vẹn, 8/58 $(13,8 \%)$ đụng dập và $4 / 58(6,9 \%)$ đứt.

3.1. Đặc điểm vị giác trước mổ. Ngưỡng phát hiện và ngưỡng phân biệt vị giác đối với tất cả các vị ở nửa lưỡi bên bệnh đều cao hơn bên lành. Sự khác biệt có ý nghĩa thống kê đối với ngưỡng phân biệt của vị ngọt $(p=0,037)$ và vị chua $(p=0,042)$ (Bảng 2).

Bảng 2. Ngưỡng vi giác trước mổ của 58 bênh nhân $\left(10^{-5} \mathrm{~g} / \mathrm{m} /\right)$.

\begin{tabular}{|c|c|c|c|c|}
\hline \multirow{2}{*}{ Vị } & \multicolumn{2}{|c|}{ Ngưỡng phát hiện } & \multicolumn{2}{c|}{ Ngướng phân biệt } \\
\cline { 2 - 5 } & Tai mố & Tai lành & Tai mố & Tai lành \\
\hline Chua & $152,6 \pm 69,1$ & $142,2 \pm 62,7$ & $325,8 \pm 150,5^{*}$ & $300,9 \pm 143,4$ \\
\hline Ngọt & $633,6 \pm 437,3$ & $560,3 \pm 345,1$ & $1461,2 \pm 1266,8^{*}$ & $1245,7 \pm 1064,3$ \\
\hline Mặn & $122,1 \pm 95,5$ & $115,2 \pm 92,7$ & $297,9 \pm 257,7$ & $284,1 \pm 256,6$ \\
\hline Đằng & $5,6 \pm 3,9$ & $5,1 \pm 3,9$ & $12,8 \pm 11,1$ & $11,8 \pm 10,3$ \\
\hline
\end{tabular}

3.2. Đặc điểm vị giác sau mổ. Tỷ lệ bệnh nhân xuất hiện thay đổi vị giác (giảm/mất và vị kim loại) sau mổ 1 ngày là $15,5 \%(9 / 58), 1$ tuần là $13,8 \%(8 / 58), 1$ tháng là $3,4 \%(2 / 58)$ và đều gặp ở các nhóm thừng nhĩ nguyên vẹn, đụng dập và đứt (Bảng 3 ). Thay đổi rõ rệt nhất là ở nhóm thừng nhĩ bị đứt, sau mổ 1 ngày và 1 tuần là $100 \%(4 / 4)$, sau 1 tháng là $50 \%(2 / 4)$, sau 3 tháng không còn bệnh nhân nào còn cảm nhận bất thường. Ở nhóm thừng nhĩ nguyên vẹn và đụng dập đều có bệnh nhân thay đổi vị giác sau 1 ngày và 1 tuần với tỷ lệ thấp và tất cả bệnh nhân này đều hết sau 1 tháng (Bảng 3).

Bảng 3. Số bệh nhân có thay đổi cảm nhận vị giác sau mổ

\begin{tabular}{|c|c|c|c|c|c|}
\hline Thừng nhĩ & $\mathbf{n}$ & $\mathbf{1}$ ngày & $\mathbf{1}$ tuần & 1 tháng & 3 tháng \\
\hline Nguyên vẹn & 46 & 3 & 1 & 0 & 0 \\
\hline Đụng dập & 8 & 5 & 4 & 0 & 0 \\
\hline Đứt & 4 & 4 & 4 & 2 & 0 \\
\hline Tống số & $\mathbf{5 8}$ & $\mathbf{9}$ & $\mathbf{8}$ & $\mathbf{2}$ & $\mathbf{0}$ \\
\hline
\end{tabular}

Ngưỡng phát hiện vị giác sau mố 1 ngày tăng với tất cả các vị đối với cả ba nhóm thừng nhĩ nguyên vẹn, đụng dập và đứt. Sau 1 tháng, nhóm thừng nhĩ nguyên vẹn còn tăng nhẹ với vị mặn và 
đắng $(p>0,05)$. Ở nhóm thừng nhĩ đụng dập, ngưỡng phát hiện còn tăng với vị chua, ngọt, đắng sau 1 tuần, vị chua và ngọt sau 1 tháng $(p>0,05)$. Thay đổi ngưỡng phát hiện vị giác rõ ở nhóm thừng nhĩ bị đứt sau 1 ngày với vị chua $(p=0,003)$, mặn $(p=0,015)$, đắng $(p=0,021)$, sau 1 tuần với vị ngọt $(p<0,001)$ và vị mặn $(p=0,028)$. Sau 1 tháng, ngưỡng phát hiện còn cao với vị mặn ( $p>0,05)$ (Bảng 4).

Bảng 4. Đối chiếu ngưỡng phát hiện vị giác $\left(10^{-5} \mathrm{~g} / \mathrm{m} /\right)$ với tổn thương thừng nhĩ.

\begin{tabular}{|c|c|c|c|c|}
\hline Thừng nhĩ & Trước mố & 1 ngày & 1 tuần & 1 tháng \\
\hline \multicolumn{5}{|c|}{ Nguyên ven } \\
\hline Chua & $200,0 \pm 173,2$ & $233,3 \pm 152,7$ & $200,0 \pm 173,2$ & $200,0 \pm 173,2$ \\
\hline Ngọt & $416,7 \pm 144,3$ & $916,7 \pm 946,5$ & $416,7 \pm 144,3$ & $416,7 \pm 144,3$ \\
\hline Mặn & $106,7 \pm 46,2$ & $133,3 \pm 46,2$ & $133,3 \pm 46,2$ & $133,3 \pm 46,2$ \\
\hline Đăng & $6,7 \pm 2,9$ & $15,7 \pm 8,7$ & $10,0 \pm 8,7$ & $10,0 \pm 8,7$ \\
\hline \multicolumn{5}{|c|}{ Đụng dập } \\
\hline Chua & $110,0 \pm 54,8$ & $180,0 \pm 130,4$ & $120,0 \pm 44,7$ & $120,0 \pm 44,7$ \\
\hline Ngot & $450,0 \pm 111,8$ & $690,0 \pm 745,3$ & $750,0 \pm 707,1$ & $550,0 \pm 273,9$ \\
\hline Mặn & $136,0 \pm 111,7$ & $208,0 \pm 107,3$ & $136,0 \pm 111,7$ & $136,0 \pm 111,7$ \\
\hline Đằng & $5,5 \pm 2,7$ & $13,0 \pm 15,2$ & $7,0 \pm 2,7$ & $5,5 \pm 2,7$ \\
\hline \multicolumn{5}{|c|}{ Đút } \\
\hline Chua & $150,0 \pm 57,7$ & $400,0 \pm 0,0^{*}$ & $350,0 \pm 300,0$ & $150,0 \pm 57,7$ \\
\hline Ngot & $562,5 \pm 314,6$ & $1650,0 \pm 1761,6$ & $2500,0 \pm 1000,0 *$ & $562,5 \pm 314,6$ \\
\hline Mặn & $80,0 \pm 0,0$ & $280,8 \pm 80,0^{*}$ & $400,0 \pm 160,0^{*}$ & $120,0 \pm 46,2$ \\
\hline Đắng & $6,3 \pm 4,3$ & $35,0 \pm 10,0^{*}$ & $20,0 \pm 14,1$ & $6,3 \pm 4,3$ \\
\hline
\end{tabular}

$(* \mathrm{p}<0,05)$

Ngưỡng phân biệt sau mổ 1 ngày tăng với tất cả các vị đối với cả ba nhóm thừng nhĩ nguyên vẹn, đụng dập và đứt. ở nhóm thừng nhĩ nguyên vẹn, ngưỡng phân biệt trở về như trước mổ trong vòng 1 tuần. Ở nhóm thừng nhĩ đụng dập, ngưỡng phân biệt còn tăng với cả 4 vị sau 1 tuần $(p>0,05)$, vị chua sau 1 tháng $(p>0,05)$. Thay đổi ngưỡng phân biệt rõ ở nhóm thừng nhĩ bị đứt sau 1 ngày với các vị chua $(p=0,003)$, mặn $(p=0,02)$ và đắng $(p=0,042)$, sau 1 tuần với vị ngọt $(p<0,001)$, mặn $(p=0,003)$, đắng $(p=0,043)$. Sau 1 tháng, ngưỡng vị giác còn cao với vị mặn $(p>0,05)$ (Bảng 5$)$.

Bảng 5. Đối chiếu ngướng phân biệt vị giác $\left(10^{-5} \mathrm{~g} / \mathrm{ml}\right)$ với tổn thương thừng nhĩ.

\begin{tabular}{|c|c|c|c|c|}
\hline Thừng nhĩ & Trước mố & 1 ngày & 1 tuần & 1 tháng \\
\hline \multicolumn{5}{|c|}{ Nguyên vẹn } \\
\hline Chua & $400,0 \pm 346,4$ & $466,7 \pm 305,5$ & $400,0 \pm 346,4$ & $400,0 \pm 346,4$ \\
\hline Ngọt & $1000,0 \pm 0,0$ & $2000,0 \pm 1732,1$ & $1000,0 \pm 0,0$ & $1000,0 \pm 0,0$ \\
\hline Mặn & $320,0 \pm 0,0$ & $426,7 \pm 184,8$ & $320,0 \pm 0,0$ & $320,0 \pm 0,0$ \\
\hline Đắng & $20,0 \pm 17,3$ & $30,0 \pm 17,3$ & $20,0 \pm 17,3$ & $20,0 \pm 17,3$ \\
\hline \multicolumn{5}{|c|}{ Đụng dập } \\
\hline Chua & $220,0 \pm 109,5$ & $360,0 \pm 260,8$ & $240,0 \pm 89,4$ & $240,0 \pm 89,4$ \\
\hline Ngọt & $1000,0 \pm 0,0$ & $1560,0 \pm 1366,8$ & $1600,0 \pm 1341,6$ & $1000,0 \pm 00$ \\
\hline Mằn & $464,0 \pm 467,8$ & $896,0 \pm 525,8$ & $528,0 \pm 465,1$ & $464,0 \pm 467,8$ \\
\hline Đắng & $14,5 \pm 14,6$ & $48,0 \pm 63,8$ & $22,0 \pm 16,4$ & $14,5 \pm 14,6$ \\
\hline \multicolumn{5}{|c|}{ Đứt } \\
\hline Chua & $350,0 \pm 100,0$ & $800,0 \pm 0,0^{*}$ & $1200,0 \pm 1346,6$ & $350,0 \pm 100,0$ \\
\hline Ngọt & $1750,0 \pm 1500,0$ & $3400,0 \pm 3417,6$ & $6000,0 \pm 2309,4 *$ & $1750,0 \pm 1500,0$ \\
\hline Mặn & $120,0 \pm 46,2$ & $960,0 \pm 369,5^{*}$ & $1280,0 \pm 905,1^{*}$ & $320,0 \pm 0,0$ \\
\hline Đắng & $12,5 \pm 5,0$ & $110,0 \pm 60,0 *$ & $50,0 \pm 20,0^{*}$ & $12,5 \pm 5,0$ \\
\hline
\end{tabular}

$(* \mathrm{p}<0,05)$

\section{BÀN LUÂN}

Ngưỡng phát hiện và phân biệt vị giác trước mổ của bên tai viêm đều cao hớn bên tai lành, đặc biệt là với vị ngọt và vị chua (Bảng 2). Nghiên cứu của một số tác giả khác cũng cho kết quả tương tự như Landis là sự thay đổi đối với vị ngọt và mặn, ${ }^{5}$ Huang và Goyal là vị đắng. 6,7 Theo Gedikli, các tổn thương viêm mạn tính của tai giữa có thể gây ra các biến đổi cấu trúc thần kinh thừng nhĩ: dày lớp vỏ thần kinh, thoái hoá dạng hốc cuả các tế bào Schwann, tăng sinh nguyên bào xơ; dẫn tới thay đổi chức 
năng vị giác. ${ }^{2}$ Tỷ lệ tổn thương thừng nhĩ ghi nhận trong phẫu thuật 58 tai gồm 79,3\% được bảo tồn nguyên vẹn, co kéo đụng dập $13,8 \%$ và $6,9 \%$ bị đứt. Kết quả này tương đồng với McManus với tỷ lệ tổn thương thừng nhĩ trong phẫu thuật tai giứa là $15-20 \%,{ }^{4}$ Huang có tỷ lệ thừng nhĩ bị đứt là $10,53 \%{ }^{6}$ Như vậy, tổn thương thừng nhĩ do viêm và can thiệp trong phẫu thuật là những yếu tố có thể ảnh hưởng đến chức năng vị giác của bệnh nhân.

Thay đổi cảm nhận vị giác gồm có nhạt miệng, đắng miệng, chua miệng và vị kim loại chủ yếu xuất hiện trong vòng một tuần sau mổ, ở cả nhóm thừng nhĩ nguyên vẹn, đụng dập và đứt, tuy nhiên tỷ lệ rối loạn vị giác cao hởn và kéo dài hơn trong nhóm thừng nhĩ bị đứt (Bảng 3). Kết quả này phù hợp với nghiên cứu hệ thống của Ziylan cho thấy rối loạn vị giác xảy ra với tỷ lệ $24 \%$ khi thừng nhĩ nguyên vẹn, 53\% khi thừng nhĩ bị phù nề đụng dập và $47 \%$ thừng nhĩ bị đứt. ${ }^{8}$ Theo chúng tôi, thay đổi vị giác ở nhóm thừng nhĩ nguyên vẹn và đụng dập là do tác dụng của lidocain $2 \%$ dùng trong phẫu thuật, phù nề hoặc thiếu máu do co kéo trong quá trình giải quyết bệnh tích ở hòm tai, gây ra nghẽn dẫn truyền thẩn kinh tạm thời ở nhiều mức độ. Trong khi đó, rối loạn do thừng nhĩ bị đứt cần nhiều thời gian hơn để có thể được bù trừ từ phía nửa lưỡi bên tai lành và nhánh lưỡi của dây thần kinh thiệt hầu. Thời gian bao lâu để bệnh nhân không còn cảm giác thay đổi vị giác là vấn đề tiếp tục tìm hiểu vì rất thay đổi, trong nghiên cứu của chúng tôi là trong vòng 3 tháng nhưng theo Sakagami là 2 năm. ${ }^{9}$

Chúng tôi nhận thấy có mối liên quan giữa thay đổi ngưỡng vị giác với các mức độ tổn thương khác nhau của thừng nhĩ (Bảng 4 và 5 ). Ở nhóm thừng nhĩ nguyên vẹn, ngưỡng vị giác với tất cả các vị đều chỉ tăng sau mổ 1 ngày và hồi phục gần như trước mổ sau 1 tuần. Ở nhóm thừng nhĩ bị đụng dập, ngưỡng phát hiện và phân biệt với 4 vị tăng chủ yếu trong 1 tuần đầu, hầu hết đều trở về gần với giá trị trước mổ sau 1 tháng, trừ ngưỡng phát hiện vị ngọt và ngưỡng phân biệt vị chua còn cao. Kết quả trên tương đồng với nghiên cứu của Berteretche cho thấy ở nhóm dây thừng nhĩ bị co kéo đụng dập, ngưỡng vị giác hồi phục sau 1 đến 6 tháng, ${ }^{3}$ chứng tỏ nhận định tăng ngưỡng vị giác chỉ có tính chất tạm thời nghẽn dẩn truyền của các sợi trục thần kinh là phù hợp. Trong khi đó, nhóm thừng nhĩ bị đứt có ngưỡng vị giác tăng cao ở mức có ý nghĩa tại các thời điểm 1 ngày, 1 tháng và chỉ trở về gần ngưỡng trước mổ sau 3 tháng.
Berteretche nhận thấy ở bệnh nhân bị cắt thừng nhĩ một bên thì ngưỡng vị giác không hồi phục hoàn toàn ngay cả sau thời gian dài là hai năm. ${ }^{3}$ Như vậy, mặc dù chức năng vị giác có thể được bù trừ theo thời gian và không phải tất cả các bệnh nhân thay đổi ngưỡng vị giác đều cảm nhâân thây khó chịu thực sự, các phẫu thuật viên vẫn cần cố gắng bảo tồn về giải phẫu cũng như hạn chế tối đa chấn thương lên thừng nhĩ nhằm giảm thiểu khó chịu cho bệnh nhân trong sinh hoạt hàng ngày.

Chúng tôi nhân thấy sự thay đổi ngưỡng phát hiện và phân biệt xảy ra chủ yếu đối với vị chua, mă̆n, đắng sau mổ 1 ngày (Bảng 4) và ngọt, mặn sau mổ 1 tuần (Bảng 5). Một số tác giả nhứ Landis nhận thấy vị ngọt và mặn bị ảnh hưởng nhiều nhất, ${ }^{5}$ Huang là vị chua và đắng, ${ }^{6}$ Goyal là vị đắng. ${ }^{7}$ Sự khác biệt về thay đổi cảm nhận với từng vị nhiều nhất có thể do đặc điểm khác nhau về tính nhạy cảm ưu thế đối với một số vị liên quan đến tuổi, giới, chủng tộc, thói quen ăn uống. Thời điểm đánh giá chức năng vị giác cũng là yếu tố ảnh hưởng kết quả đánh giá, vì nghiên cứu cho thấy chu trình đổi mới của các tế bào vị giác là khoảng 10 ngày, ngoài ra sau 46 tuổi các nụ vị giác thoái hoá nhanh khiến khả năng phân biệt vị giác cũng giảm đi. ${ }^{10}$

\section{KẾT LUÂN}

Thay đổi ngưỡng vị giác chủ yếu xảy ra trong vòng 1 tháng sau mổ. Ngưỡng vị giác tăng cùng mức độ tổn thương thừng nhĩ, tỳ lệ cao và kéo dài nhất với nhóm thừng nhĩ bị đứt, ảnh hưởng rõ nhất với vị mặn và chua. Sau 3 tháng, không còn bệnh nhân nào có cảm giác thay đổi vị giác. Bảo tồn giải phẫu và hạn chế tối đa chấn thương thừng nhĩ là việc làm cần thiết để giảm thiểu ảnh hưởng đến chức năng vị giác của bệnh nhân.

\section{Xung đột lợi ích: Không}

Lời cảm ơn. Xin chân thành cảm ơn Khoa Tai Mũi Họng, Bệnh viện Bạch Mai, Khoa Tai và Tai thần kinh, Bệnh viện Tai Mũi Họng Trung ương và Bộ môn Dược lí, Trường Đại học Y Hà Nội đã giúp đỡ chúng tôi thực hiện nghiên cứu này.

\section{TÀI LIẸU THAM KHẢO}

1. Doty RL. Treatments for smell and taste disorders: A critical review. Handbook of clinical neurology. 2019;164:455-479.

2. Gedikli O, Doğru $H$, Aydin $G$, et al. Histopathological changes of chorda tympani in chronic otitis media. Laryngoscope. Apr 2001; 111(4 Pt 1):724-727.

3. Berteretche MV, Eloit C, Dumas $\mathbf{H}$, et al. Taste deficits after middle ear surgery for otosclerosis: taste somatosensory interactions. European journal of oral sciences. Oct 2008;116(5):394-404. 
4. McManus LJ, Dawes PJ, Stringer MD. Clinical anatomy of the chorda tympani: a systematic review. J Laryngol Otol. Nov 2011;125(11):1101-1108.

5. Landis BN, Beutner D, Frasnelli J, et al. Gustatory function in chronic inflammatory middle ear diseases. Laryngoscope. Jun 2005;115(6):1124-1127.

6. Huang CC, Lin CD, Wang CY, et al. Gustatory changes in patients with chronic otitis media, before and after middle-ear surgery. The Journal of laryngology and otology. May 2012;126(5):470-474.

7. Goyal A, Singh PP, Dash G. Chorda tympani in chronic inflammatory middle ear disease.
Otolaryngology--head and neck surgery: official journal of American Academy of OtolaryngologyHead and Neck Surgery. May 2009;140(5):682-686.

8. Ziylan F, Smeeing DPJ, Bezdjian $A$, et al. Feasibility of preservation of chorda tympani nerve during noninflammatory ear surgery: A systematic review. The Laryngoscope. Aug 2018;128(8):1904-1913.

9. Sakagami $\mathbf{M}$, Sone $M$, Tsuji $K$, et al. Rate of recovery of taste function after preservation of chorda tympani nerve in middle ear surgery with special reference to type of disease. The Annals of otology, rhinology, and laryngology. Jan 2003; 112(1):52-56.

\section{ĐÁNH GIÁ HIÊ̂U QUẢ BAN ĐẦU KIỂM SOÁT CẬN THI! TRÊN TRÊ EM BẰNG ATROPIN 0.01\%}

\section{TÓM TẮT}

Mục tiêu: Đánh giá hiệu quả ban đầu kiểm soát cân thị của Atropin $0.01 \%$ trên trẻ cận thị tăng số nhanh và tìm hiêu một số yếu tố liên quan đến hiệu quả kiểm soát cận thị bằng thuốc Atropin $0.01 \%$. Đối tượng và phưởng pháp nghiên cứu: nghiên cứu thử nghiệm lâm sàng không có nhóm chứng, nghiên cứu được thực hiện trên 54 mắt có tốc độ tiến triển cận thị trên $1.00 \mathrm{D} /$ năm tại khoa khúc xạ bệnh viện Trung ương. Kết quả: Tất cả các trường hợp sau khi tra Atropin $0.01 \%$ đều không có biểu hiện lóa mắt, đỏ mắt và khó nhìn gần. Tốc độ tiến triển cân thị: sau 6 tháng dùng thuốc tốc độ tẳng công suất cận trung bình là $0.62 \pm 0.69 \mathrm{D} /$ nằm $(\mathrm{p}<0.001)$, sau 12 tháng dùng thuốc tốc độ tăng công suất cận trung bình là $0.47 \pm 0.43 \mathrm{D} /$ năm $(\mathrm{p}<0.001)$. Trục nhãn cầu: sau 6 tháng dài thêm $0.18 \pm 0.11 \mathrm{~mm}(p<0.001)$, so với thời điểm 6 tháng, sau 12 tháng dài thêm $0.15 \pm 0.82$ $\mathrm{mm}(\mathrm{p}>0.05)$. Biên độ điều tiết giảm sau 2 tuần sử dung thuốc, hồi phục sau 6 tháng và 12 tháng dùng thuốc. Kích thước đồng tử giãn nhe sau 2 tuân sứ dung thuốc, hồi phục sau 6 tháng và 12 tháng dùng thuốc. Kết luân: Sử dụng Atropin $0.01 \%$ làm giảm tốc độ tiến triến cận thị và không gây ảnh hưởng đến việc nhìn gần của trẻ.

Tư khóa: kiểm soát cận thị, Atropin 0.01\%.

\section{SUMMARY \\ ASSESSMENT OF CORNEAL REFRACTION \\ POWER AND AXIS LENGTH IN HIGH MYOPIA}

Objective: Assessing the initial effectiveness of myopia control by Atropin $0.01 \%$ on rapidly increasing myopia children and find out some factors related to the effectiveness of myopia control with Atropin

${ }^{1}$ Bệnh viện Mắt Trung Uơng

Chịu trách nhiệm chính: Nguyễn Thị Thu Hiền

Email: thuhienvnio@gmail.com

Ngày nhận bài: 5.01.2021

Ngày phản biện khoa học: 8.3.2021

Ngày duyệt bài: 16.3.2021

\section{Nguyễn Thị Thu Hiền', Trần Phương Anh ${ }^{1}$}

$0.01 \%$. Research methods: clinical trial studies without control group, the study was conducted on 54 eyes with a myopia progress rate of over $1,00 \mathrm{D} /$ year in the refraction department of Vietnam National Eye Hospital. Results: All cases after using Atropin 0.01\% were no glare, redness, and difficulty in near vision. Myopia progress rate: after 6 months of using Atropin $0.01 \%$, the average rate of increase in myopia power was $0.62 \pm 0.69 \mathrm{D} /$ year, after 12 months of using the drug, the average rate of increase in myopia power was $0.47 \pm 0.43 \mathrm{D} /$ year. Axis length: after 6 months it was longer $0.18 \pm 0.11 \mathrm{~mm}(p<0.001)$, compared to 6 months, after 12 months it was longer $0.15 \pm$ $0.82 \mathrm{~mm}$ ( $p>0.05)$. The accommondation amplitude decreased after 2 weeks of using Atropin 0.01\%, recovered after 6 months and 12 months of dropping the drug. The pupil size dilated slightly after 2 weeks of using Atropin $0.01 \%$, recovered after 6 months and 12 months of dropping the drug. Conclusion: After using Atropin $0.01 \%$ in myopia children, the rate of myopia progress decreased and near vision was not affectted.

Key words: myopia control, Atropin $0.01 \%$.

\section{I. ĐẶT VẤN ĐỀ}

Cận thị trẻ em đang là vấn đề được cả xã hội quan tâm vì tỷ lệ cận thị trẻ em ngày càng tăng nhanh. Cận thị trẻ em ngày càng xuất hiện sớm và tiến triển nhanh dẫn đến tỷ lệ cận thị cao cũng tăng theo. Dự đoán đến năm 2050, tỷ lệ cận thị sẽ tăng lên đến $52 \%$ dân số thế giới (khoảng 5 tỷ người), trong đó cận thị cao chiếm 10\% (khoảng 911 triệu người). Đây sẽ là 1 gánh nặng rất lớn khi tỷ lệ cận thị và cận thị cao chủ yếu nằm ở nhóm thanh thiếu niên, lứa tuổi lao động chính, đặc biệt là ở các nước Đông nam Á, trong đó có Việt Nam.

Trên thế giới, các biện pháp kiểm soát tiến triển của cận thị đang được quan tâm ở nhiều 